\title{
La construcción del poder hídrico: agroexportadores y escasez de agua subterránea en el valle de Ica y las pampas de Villacurí
}

\section{Gerardo Damonte}

Grupo de Análisis para el Desarrollo

Pontificia Universidad Católica del Perú

\section{Isabel Gonzales}

Pontificia Universidad Católica del Perú

\section{Julieta Lahud}

Pontificia Universidad Católica del Perú

\section{RESUMEN}

El boom agroexportador en la región costera de Ica ha provocado dos procesos interrelacionados: la generación situaciones de estrés hídrico y la emergencia del grupo agroexportador como un nuevo actor social. El papel asignado a los agroexportadores en la narrativa de desarrollo regional les ha concedido una posición dominante en la gestión de los recursos hídricos de Ica. Esto ha generado una reconfiguración de las relaciones sociales y politicas en el espacio local, que ha permitido que el grupo agroexportador sea incluso capaz de disputar los esfuerzos de regulación del agua subterránea del Estado. Así, las preguntas que guian esta investigación son: ¿cómo los agroexportadores han concentrado poder hídrico en Ica? ¿Cómo ejercen este poder? El articulo argumenta que el control sobre el agua subterránea ha recaído en manos del grupo agroexportador gracias a su capacidad de concentrar y ejercer tres dimensiones de poder: la capacidad económica, el conocimiento técnico y la coerción. En el desarrollo de este argumento, se explica cómo la concentración de estas dimensiones de poder ha incidido 
en la producción de escenarios de escasez hídrica a determinados grupos de población, sin enfrentar mayor resistencia a pesar de ello.

Palabras clave: poder hidrico, escasez hidrica, agroexportación, Estado, Ica-Perú.

\title{
The Constitution of Water Power: Agro-exporters and groundwater scarcity in the Ica Valley and Pampas de Villacurí
}

\author{
ABSTRACT
}

The agro-export boom in the coastal region of Ica has caused two interrelated processes: the generation of water scarcity scenarios and the emergency of the agro-exporter group as a new social actor. The role assigned to agro-exporters in the narrative of regional development has given them a dominant position in the management of Ica water resources. This has generated a re-configuration of social and political relationships at the local space that has allowed them to be able of even contest State's efforts to regulate groundwater use. Thus, the questions guiding this research are: how the agro-exporter group has concentrated water power in Ica? And how do they exercise this power? This paper argues that control over groundwater resources has fallen into the hands of the agro-exporter group due to their capacity to concentrate and exercise three dimensions of power: economic capacity, technical knowledge and coercion. In developing this argument, we explain how the concentration of these power dimensions has influenced in the production of water scarcity scenarios to certain groups of population, without confronting much resistance despite of it.

Keywords: water power, water scarcity, agro-exports, State, IcaPerú. 


\section{INTRODUCCIÓN}

A principios de siglo, la región costera de Ica empezó a consolidarse como el principal escenario de lo que medios de comunicación y figuras políticas bautizaron como «el milagro agroexportador». Este milagro estuvo caracterizado por el reverdecimiento de vastos espacios desérticos por medio de la inserción de la agricultura moderna; el incremento exponencial de las exportaciones de productos no tradicionales, en particular el espárrago; la cada vez mayor participación de la agroexportación en la generación de divisas en los niveles regional y nacional, y la emergencia del grupo agroexportador como un nuevo e importante actor social regional y nacional.

Tan solo unos años después, este milagro se vio amenazado por su propio accionar. La sobreexplotación del acuífero de Ica, Villacurí y Lanchas por la producción masiva de productos de exportación produjo un ciclo de descenso del nivel del agua subterránea que impactaría en la generación de escenarios de escasez hídrica para distintos usuarios de la región (Oré, Bayer, Chiong y Rendón, 2012; Marshall, 2014). En respuesta a esta situación, en el año 2005 el gobierno regional de Ica impuso una veda prohibiendo la perforación de nuevos pozos de agua subterránea con fines de uso agrícola. Esta veda sería refrendada, ampliada y endurecida en distintas ocasiones, como parte de los esfuerzos del Estado para detener la sobreexplotación del acuífero y gestionar su recuperación. Sin embargo, en este proceso el Estado encontró serias dificultades para vigilar y sancionar las operaciones irregulares de los principales usuarios de agua subterránea: el grupo agroexportador (Muñoz, 2015). Este problema surgiría frente a la existencia de un desbalance de poderes, en un contexto en el que el grupo agroexportador ha logrado posicionarse como un actor dominante en términos políticos y económicos en la región (Damonte, 2015). 
Las preguntas que guían esta investigación son: ¿cómo los agroexportadores han concentrado poder hídrico en Ica? y ¿cómo ejercen este poder? Este artículo argumenta que el poder hídrico en Ica surge a partir del control del agua subterránea, control que ha recaído en manos del grupo agroexportador gracias a su capacidad de concentrar y ejercer tres dimensiones de poder: la capacidad económica, el conocimiento técnico y la coerción. En el desarrollo de este argumento, se muestra que el dominio de los agroexportadores sobre otros actores y la primacía en el control de los recursos hídricos no es una facultad arrebatada, sino otorgada y legitimada por discursos de eficiencia en el uso de agua y desarrollo regional, aún en un contexto de estrés hídrico.

\section{MARCO TEÓRICO Y METODOLOGÍA}

\section{Marco teórico}

El poder hídrico puede ser comprendido como aquel que emerge de la relación simbiótica entre el control de las fuentes de agua y la posición dominante de determinados actores sociales. La relación entre agua y poder fue inicialmente explorada en el trabajo clásico de Witffogel (1957), donde se expone que en las sociedades agrarias el poder de las élites se construyó sobre la base del control exclusivo del acceso al agua de riego. Este poder se intensificaría en entornos áridos, donde la necesidad de infraestructura de gran escala llevaría a la consolidación de élites en Estados centralizados y muchas veces deriva en el establecimiento de Estados despóticos.

Elaboraciones posteriores de esta teoría sostendrían que en las sociedades capitalistas neoliberales contemporáneas el argumento sería válido no solo para el Estado y las sociedades agrarias, sino también para otro tipo de actores que logran hacerse del control de los recursos hídricos, tales como empresas transnacionales de agua potable (Swyngedouw, 2004, 2006), empresas agroindustriales (Wortser, 1985; Oré y Damonte, 2014; Damonte, 2015; Peña, 2011; Wester y Hoogesteger, 2011), empresas mineras y de hidrocarburos (Perreault, 2007, 2013) e hidroeléctricas (Yacoub, Duarte y Boelens, 2015).

Pero ¿cómo se construye el poder hídrico? Proponemos que el poder hídrico, en el caso de Ica, se genera a partir del ejercicio de tres dimensiones interrelacionadas de poder: la capacidad económica, el conocimiento técnico y la capacidad coercitiva. 
Por capacidad económica nos referimos a la disposición del capital financiero requerido para adquirir medios de producción, fuerza de trabajo y generar ganancias (Harvey, 1990). En el caso de la agroexportación en Ica, los principales medios de producción son la tierra $-\mathrm{y}$, más aún, el agua subterránea-, pero también la tecnología e infraestructura necesarias para garantizar el acceso, sea mediante pozos tubulares, instalación de sistemas de riego por goteo o infraestructura hídrica de mayor escala. En un contexto donde el acceso a esta fuente particular de agua está condicionado por la disponibilidad financiera de los usuarios, la capacidad económica se traduce en control hídrico, al facilitar su acumulación y concentración en las manos de determinados grupos.

El conocimiento técnico como poder se fundamenta en la propuesta de Foucault (1992) sobre la relación dialéctica entre poder y saber. En esta se propone que la verdad es un mecanismo de poder en tanto los discursos hegemónicos y sus portadores se elevan sobre otros discursos y actores, reclamando el derecho legítimo a nombrar las cosas. En el caso del agua, el enfoque técnico-científico se ha vuelto hegemónico y se manifiesta en discursos de eficiencia y racionalidad que legitiman regímenes de valoración económica del agua, soslayando otros tipos de usos y valoraciones (Boelens, 2011; Boelens, Getches y Guevara, 2006; Yacoub et al., 2015).

Otro aspecto de la relación poder-saber revela la importancia de la producción de conocimiento para dar legibilidad a determinados fenómenos y a la vez crear objetos de intervención con el fin establecer dominio (Foucault, 2006; Agrawal, 2005). Así, la elaboración de censos, acciones de regulación y programas de planeamiento y desarrollo para la gestión del agua subterránea se pueden ver como medidas que buscan generar conocimiento con el fin de ejercer de forma efectiva el gobierno del agua y sus usuarios.

Por capacidad coercitiva entendemos la potestad de algunos actores para condicionar el comportamiento de otros por medios represivos. La represión se puede dar tanto en el nivel objetivo como en el subjetivo. En el primero se da mediante el ejercicio, o amenaza del ejercicio, de la violencia física, entendida como el uso de la fuerza que busca hacer daño; en el segundo, mediante la sanción social en forma de aislamiento, deshonor o pérdida de la buena reputación personal producto de la subversión de mandatos sociales ampliamente aceptados (Springer, 2012; Bourdieu y Passeron, 2001; Foucault, 2001). En el caso del agua, la coerción se puede dar a través del uso de la violencia física o la desacreditación y compromiso de la buena reputación de las personas, como medio para obstaculizar las acciones de vigilancia de las autoridades y miembros de la sociedad civil. 
Las dinámicas en torno al poder hídrico solo pueden entenderse si se considera la relación Estado-sociedad, que es el espacio donde se definen las prácticas institucionalizadas para el acceso y uso al agua. Siguiendo a Migdal (1988), el Estado puede ser definido como una metaorganización diseñada para regular las estrategias e intereses de los diversos grupos que conforman la sociedad. Así, el Estado debe ser visto como un actor en la sociedad y no fuera de ella, que en algunos casos tiene la posibilidad de participar en los intereses de grupos particulares y beneficiarlos, y en otros, de oponerse y desafiarlos (Durand, 2003, 2005, 2012), siendo un espacio que presenta contradicciones, tensiones y conflictos entre sus distintas agencias y niveles (Migdal, 1988; Dargent, 2015; Patriau, 2014).

En este marco, la institucionalidad formal del Estado, expresada en normas y respaldada por canales oficiales, evidencia una constante interacción con la institucionalidad informal de la sociedad basada en reglas sociales compartidas que no son legitimadas ni sancionadas por canales oficiales, sino por la comunidad o grupos sociales, y hasta a veces con la ilegalidad, presentando una continuidad donde se hace difícil dilucidar los márgenes de lo uno y lo otro (Helmke y Levistky, 2003; Das y Poole, 2004; Sindzingre, 2004).

\section{Metodología}

La metodología de investigación fue de carácter cualitativo (Hammersley y Atkinson, 1994; Denzin y Lincoln, 2011) y se usó el método etnográfico (Guber, 2001), que resulta pertinente para el estudio de las dinámicas del poder y del discurso. Así, los insumos principales de este estudio fueron los testimonios de los diversos actores involucrados en la gestión del agua en Ica y la observación de prácticas, eventos, discusiones y escenarios agrícolas en el campo.

La recolección de datos supuso la ejecución de un trabajo de campo entre los meses de agosto y septiembre del año 2015 en la zona del valle de Ica y pampas de Villacurí, región de Ica debajo de la cual se ubica el acuífero del mismo nombre. Ambas áreas han tenido como actividad principal la agroexportación basada en la extracción de recursos hídricos subterráneos, por lo cual el acuífero es considerado como el sistema que mayor explotación ha sufrido en el país en la última década ${ }^{1}$.

Presentación Plan de gestión del acuifero del valle de Ica y pampas de Villacurí y Lanchas, agosto de 2015. 
Durante el trabajo de campo se realizaron entrevistas a profundidad, individuales y grupales, a funcionarios de la Autoridad Nacional del Agua - ANA; Autoridades Locales del Agua - ALA de Ica y de Río Seco; funcionarios de la Autoridad Administrativa del Agua - AAA Cháparra-Chincha; autoridades distritales y regionales; directivos de juntas de usuarios de aguas subterráneas: la Junta de Usuarios de Aguas Subterráneas del Valle de Ica - JUASVI y la Junta de Usuarios de Agua Subterránea de Río Seco - JURS; directivos de las juntas de usuarios de aguas superficiales: la Junta de Usuarios del Río Ica - JUDRI y la Junta de Usuarios de Riego de La Achirana Santiago de Chocorvos - JURLASCH, así como a comisiones de usuarios y pequeños agricultores particulares. Además, se recogió información secundaria de instituciones, medios de comunicación y organizaciones locales.

El texto está dividido en tres partes que exploran las dimensiones de poder hídrico planteadas. En la primera se trata la capacidad económica y su vínculo con las dinámicas de concentración de tierra y agua subterránea. En la segunda se trata el conocimiento técnico, donde se analiza el vínculo entre los discursos de eficiencia, el manejo de información y el control del agua. En la tercera se trata la capacidad coercitiva como medio de consolidación del acceso poco restringido a los recursos hídricos subterráneos de Ica. Finalmente, la cuarta parte explica los principales hallazgos a modo de conclusiones.

\section{AGROEXPORTACIÓN, PODER Y ESCASEZ HÍDRICAEN ICAY VILLACURÍ}

\section{Capacidad económica: concentración de tierra y agua}

A partir de la década de 1990, en un contexto de instauración de reformas neoliberales con las que el Estado emprendió un camino de apertura hacia los mercados globales, la costa peruana empezó a proyectarse como un espacio privilegiado para el desarrollo de cultivos a gran escala dirigidos al mercado internacional de alimentos (Gómez, 2008). Esta visión se consolidaría con la emisión del decreto ley 653, de Promoción de las Inversiones en el Sector Agrario, con el que el Estado buscó fomentar la venta a bajos precios de tierras clasificadas como eriazas ${ }^{2}$ a quienes se comprometieran a invertir en ellas para volverlas productivas.

2 «Se consideran tierras eriazas las no cultivadas por falta o exceso de agua y demás terrenos improductivos excepto: a. Las lomas y praderas con pastos naturales dedicados a la ganadería, aun cuando su uso fuese de carácter temporal. b. Las tierras de protección, entendiéndose por tales, las que no reúnan las condiciones ecológicas, mínimas, requeridas para cultivo, pastoreo 
En Ica, zona desértica de la costa peruana, la productivización de la tierra estuvo ligada a la extracción del agua subterránea - recurso de mejor calidad, cantidad y disponibilidad en la zona y cuyo uso estuvo prácticamente desregulado hasta el año $2009^{3}$ - , por medio de pozos tubulares. Dado que la instalación de este tipo de pozos demandaba grandes inversiones de dinero, las principales beneficiarias del decreto ley 653 fueron grandes empresas agroexportadoras de capitales nacionales e internacionales, pues gracias a aquel lograron acceder a amplias extensiones de tierra, facultándolas para el cultivo de productos de exportación como el espárrago, la uva de mesa y la páprika.

Debido a la creciente demanda internacional de productos experimentada durante la primera década del presente siglo, las tierras adquiridas en un inicio por las empresas agroexportadoras se volvieron insuficientes. En este contexto, los agroexportadores del valle de Ica optaron por expandirse territorialmente mediante la compra masiva de las parcelas agrícolas próximas a sus fundos, de pequeños y medianos agricultores y ex cooperativistas, así como por medio del arriendo de tierras, sobre todo en los períodos en que la demanda de productos superó la capacidad de la propiedad agroindustrial. Por su parte, en la zona de Villacurí la expansión territorial de los agroexportadores siguió adelante, principalmente mediante la adquisición de tierras eriazas (ver mapa 1). Así, en el período 1994-2012, en la provincia de Ica, la propiedad agraria entre las $100 \mathrm{y}$ las 500 hectáreas se incrementó en un 19,67\%, mientras que la propiedad de 500 hectáreas a más creció en un 347,90\% (INEI, 1994, 2012).

El proceso de expansión de la propiedad agrícola en Ica trajo consigo la necesidad de contar con la disponibilidad de mayores volúmenes de agua subterránea para la habilitación de las nuevas parcelas. Se buscó suplir la creciente demanda con el despliegue de tres estrategias: la compra de pozos en mal estado para su reparación y uso; la compra de tierras con pozos para la conducción de agua desde distintos puntos hacia los fundos, y la perforación de nuevos pozos (Damonte, Pacheco y Grados, 2014).

o producción forestal; y, c. Las que constituyan patrimonio arqueológico de la Nación» (DL $653,1991)$.

3 Año en que se emite la Ley de Recursos Hídricos 29338. 

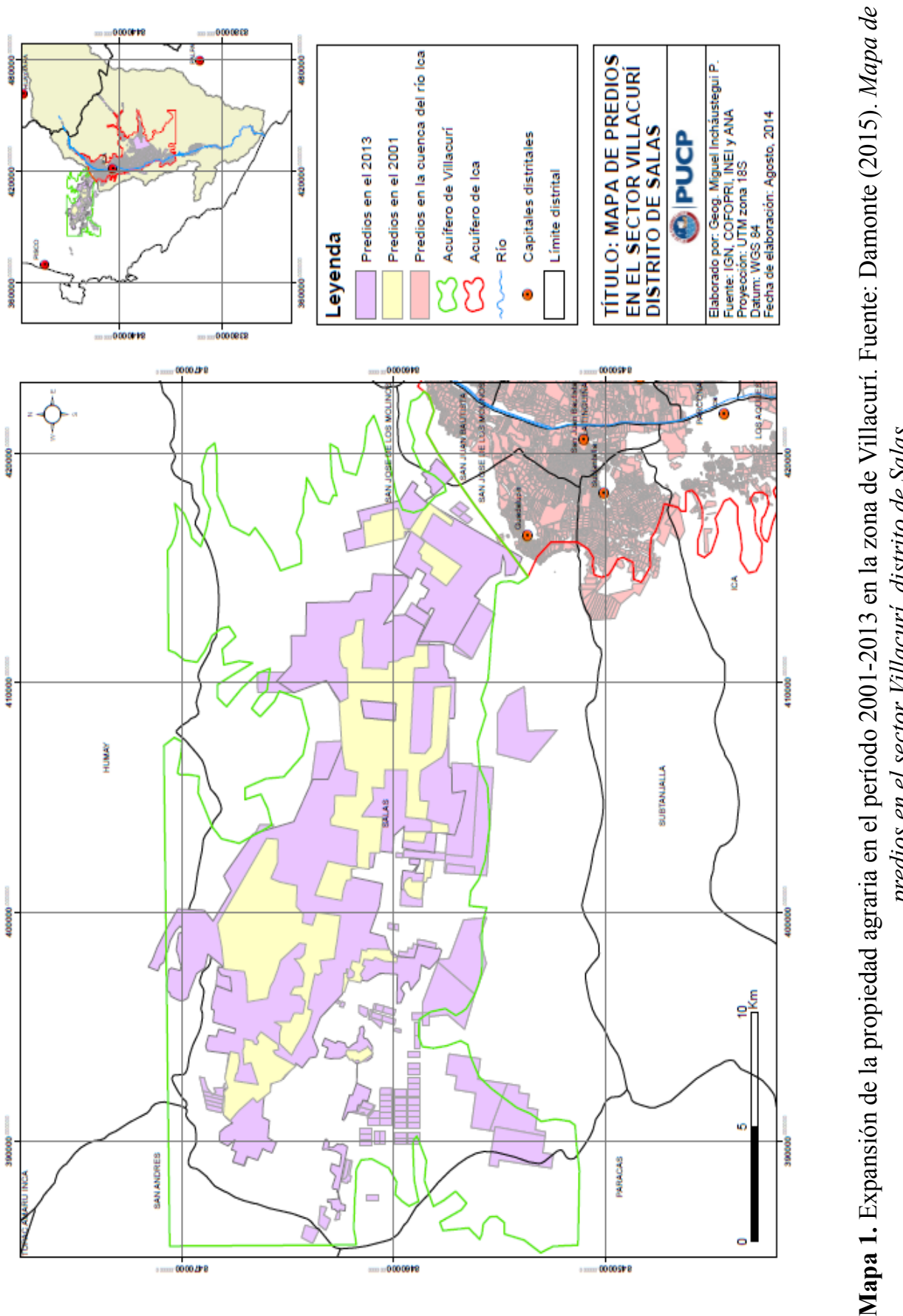
La ampliación continua de la frontera agrícola y la producción intensiva de productos con alta demanda de agua, como el espárrago y la vid, impactaron en el inicio de un ciclo de descenso alarmante del nivel de agua del acuífero del valle de Ica y Villacurí, tal como se muestra en la tabla 1. Como consecuencia, muchos agricultores vieron sus pozos quedar sin acceso al agua por falta de profundidad, mientras que otros sufrieron la salinización de sus fuentes de agua, que perdieron aptitud para la producción de determinados cultivos. Esta situación ha generado escenarios de escasez, sobre todo en el caso de los usuarios que no pudieron profundizar sus pozos - cuando aún estaba permitido hacerlo - o conducir agua desde otras fuentes no salinizadas, debido al alto costo de estas obras.

Tabla 1. Reserva explotable del acuífero de Ica, Villacurí y Lanchas y nivel de explotación (2009 -2014)

\begin{tabular}{lccccccc}
\hline Acuífero & $\begin{array}{c}\text { Reserva } \\
\text { explotable } \\
\text { (/año) }\end{array}$ & $\begin{array}{c}\text { Explotación } \\
\text { (/año) }\end{array}$ & $\begin{array}{c}\text { Explotación } \\
\text { (/año) }\end{array}$ & $\begin{array}{c}\text { Sobrex- } \\
\text { plotación } \\
\text { (/año) } \\
2009\end{array}$ & $\begin{array}{c}\text { Sobrex- } \\
\text { plotación } \\
\text { (/año) } \\
2013-2014-2014\end{array}$ & $\begin{array}{c}\text { Vol. } \\
\text { otorgado } \\
\text { (/año) }\end{array}$ & $\begin{array}{c}\text { Vol. } \\
\text { asignable } \\
\text { (/año) }\end{array}$ \\
\hline Ica & 189 & 335 & 220 & -146 & -31 & 134,14 & 54,86 \\
Villacurí & 63 & 228 & 188 & -165 & -125 & 87,8 & $-24,8$ \\
Lanchas & 17 & 42 & 53 & -25 & -36 & 3,5 & 13,5 \\
\hline
\end{tabular}

Fuente: ANA (2015) Presentación Plan de Gestión del acuífero de Ica, Villacurí y Lanchas.

A pesar de haber afectado en principio a pequeños y medianos agricultores sin capacidad financiera para mitigar los efectos del descenso hídrico, las proyecciones de la ANA sobre el tiempo de vida útil de los pozos de Ica pronosticaron que, de mantenerse el nivel de explotación actual, muchas zonas de producción agroindustrial estarían perdiendo el acceso al agua en tan solo unos pocos años ${ }^{4}$. Esto ha alarmado a todos los sectores del agro iqueño, así como a autoridades y funcionarios de los gobiernos regional y nacional, quienes perciben una amenaza a la continuidad de la agroexportación en la región.

\footnotetext{
4 http://www2.congreso.gob.pe/sicr/comisiones/2012/com2012ciencia.nsf/0/1187fd07847ff5b c05257b5f00779859/\$FILE/07_Situacion_Acuiferos_Ica.pdf
} 
En este escenario, a partir de la segunda mitad de la década de 2000, el grupo agroexportador de Ica vio por conveniente asociarse en juntas de usuarios ${ }^{5}$ con el fin de promover la ejecución de proyectos de recarga del acuífero por el Estado. El Estado, cada vez menos dispuesto a invertir fondos públicos en grandes proyectos de infraestructura pero deseoso de captar inversión privada, ha buscado desde entonces promover una serie de proyectos que beneficiarían a la agroexportación iqueña bajo la modalidad de inversión de asociación público-privada - $\mathrm{APP}^{6}$.

Este nuevo esquema de inversión requeriría que los proyectos de infraestructura hidráulica contasen con un margen de rentabilidad económica derivado del cobro de una retribución económica a los usuarios. Tanto para el Estado como para el grupo agroexportador iqueño asumir este costo es considerado como un acto moral frente a la responsabilidad de los últimos en la degradación del acuífero. Tal como afirmaba un miembro de la JURS sobre la ejecución de un proyecto de recarga que buscaría la conducción de los excedentes del río Pisco, en la provincia de Pisco, a zonas de recarga en las Pampas de Villacurí, en la provincia de Ica:

[...] el Estado no quiere cubrir el gasto completo de todo el proyecto. Realmente es poco probable y también, yo creo, personalmente, que no tenemos que esperar que todo nos dé el Estado, y más aún si somos una empresa privada que exporta. Yo soy la que está degradando el acuífero, estoy sobrexplotando, y como ya me lo acabé, ¿voy a querer que el Estado me ponga la obra completa? (JURS).

Sin embargo, la ejecución de nueva infraestructura bajo la modalidad APP podría terminar siendo una manera más de consolidar el control del grupo exportador sobre los recursos hídricos subterráneos, al hacerlos accesibles únicamente a quienes pueden pagar por ellos.

Sorprendentemente, los procesos de concentración de tierra y agua han encontrado poca resistencia en los pequeños y medianos agricultores locales y en las juntas de usuarios que los representan. Esto tendría dos explicaciones. En primer lugar, un grupo importante de pequeños agricultores se ha visto beneficiado económicamente por la presencia de las empresas agroexportadoras. Unos han visto como una oportunidad de diversificación de ingresos la oferta laboral

\footnotetext{
5 Las juntas de usuarios son asociaciones civiles sin fines de lucro, representativas de todos los usuarios de agua de un sistema o sector hidráulico común (artículo 20 del Reglamento de organizaciones de usuarios de agua).

6 Entre ellos los proyectos de afianzamiento hídrico de la cuenca de río Pisco-río Seco.
} 
temporal que ofrecen los fundos de sus localidades, mientras que otros se han beneficiado con la venta o arriendo de sus tierras.

La gente que ha vendido aduce que está bien que la empresa haya venido, que le está dando trabajo a la gente, que la gente ya no se va [...]. Verdaderamente la población necesita, da trabajo a la gente, ya la gente tiene mayores ingresos. Aunque es verdad que también hay un poco de abuso, pero la gente a veces así lo quiere [...] (agricultor del centro poblado Pinilla).

En segundo lugar, los agroexportadores han creado relaciones de mutuo beneficio con las juntas de usuarios de aguas superficiales que representan a los pequeños y medianos agricultores. En el ámbito particular, algunos agroexportadores se han vuelto usuarios de aguas superficiales con el fin de infiltrarlas en sus fundos. Ellos son considerados por estas juntas como buenos usuarios, dado que pagan «voluntariamente» una retribución económica, a diferencia de otros, que extraen el agua directamente del subsuelo y «se la llevan gratis», invisibilizando sus conexiones con el flujo de agua superficial. Como comentaba un directivo de la Junta de Usuarios del Río Ica:

[...] tenemos algunas buenas agroexportadoras que, bajo el concepto de eficiencia y buen uso de agua, como Agrocasa, nos compran el agua en excedencia. Con algunas otras, llamémoslas, buenas agroexportadoras, hacemos convenios. Por ejemplo, con QF en la parte alta, si bien es cierto no nos compran el agua, hacen trabajos bajo su peculio para tener mayor recarga. Yo creo que ese trabajo realmente es el que estamos buscando como organización: más que desentendernos con las agroexportadoras es buscar una alianza (directivo JUDRI).

De igual manera, en el plano colectivo los agroexportadores, por medio de las juntas de usuarios de aguas subterráneas - y en particular la JUASVI — han establecido acuerdos de apoyo interinstitucional con las juntas de usuarios de aguas superficiales, como la JURSLACH y la JUDRI. Mediante estos acuerdos, los primeros han invertido en proyectos y estudios dirigidos a la mejora y mantenimiento de infraestructura a cambio de la asignación de los excedentes para su uso en proyectos de recarga artificial que les permitan mantener sus niveles regulares de extracción de agua.

Así, un contexto de descenso del nivel del agua del acuífero generado por la explotación intensiva del agua subterránea por la agroexportación, la dependencia del acceso al agua respecto de la disponibilidad de recursos financieros de los usuarios para invertir en infraestructura y pagar derechos de uso de agua contribuye a 
la agudización de inequidades en la distribución del agua a medida que prioriza la asignación de aguas subterráneas y excedentes superficiales a los usuarios con mayores recursos, mientras que se generan escenarios de despojo y escasez hídrica entre los productores agrícolas de menores recursos. Esta situación se invisibiliza bajo la aparente neutralidad de los regímenes económico-productivos del agua y los discursos de eficiencia que serán explorados a continuación.

\section{Conocimiento técnico: uso eficiente del agua, manejo de información y competencia por la gestión de los recursos hídricos}

La ampliación de la frontera agrícola alcanzada gracias a la implementación tecnológica para la extracción de agua subterránea transformó el significado del dicho «arar en el desierto». Hoy el reverdecido paisaje agrícola del valle de Ica y las pampas de Villacurí se ha transformado en evidencia del triunfo del hombre sobre la naturaleza, en símbolo de desarrollo y modernidad en el agro y en fuente del orgullo regional iqueño. Dentro de la narrativa generalizada, el grupo agroexportador se ve como el principal motor de desarrollo regional, en la medida en que se considera consecuencia directa de la iniciativa autónoma de inversión y conocimiento técnico de los empresarios agroexportadores. Tal como señalaba un representante de la JURS:

Ahora, Ica ha dado el espaldarazo al Perú convirtiéndose en la primera región agroexportadora y le hizo abrir los ojos a toda la franja costera desde Tumbes a Tacna. Ellos dijeron «por qué Ica y nosotros no, siendo más grandes». Pero quién lo hizo, ¿el gobierno?, no. Ni este, ni el anterior, ni el anterior. Lo ha hecho el empresariado privado, la empresa privada. Acá había todo un centro vitivinícola que ha quedado abandonado y nada ha hecho el Estado, los diferentes gobiernos y menos aún en temas de irrigaciones (directivo de la JURS).

En este proceso, los agroexportadores han logrado incorporar en su práctica productiva los discursos técnicos sobre uso eficiente y racional del agua gracias al uso de riego tecnificado por goteo y pulso. La eficiencia en el riego aquí es concebida como la capacidad de hacer uso de la menor cantidad posible de agua, para obtener una mayor producción (cantidad) y productividad (relación precio/ producto), así como el no permitir que «ni una gota de agua se vaya al mar», por lo que la eficiencia se vincula principalmente con la idea de un uso económicamente racional del agua. 
En el contexto de escasez hídrica de Ica, y ante la existencia de una política general de uso eficiente del agua, la instalación de sistemas de riego tecnificado por goteo para los agroexportadores ha sido visto con simpatía por el Estado, a pesar de que su uso no signifique una disminución en el uso intensivo de los recursos hídricos debido a su tendencia a la expansión de la frontera agrícola ${ }^{7}$. En este marco, la eficiencia se ha vuelto un significante vacío que ha permitido que los intereses del Estado se alineen con los intereses de los agroexportadores, mientras que los pequeños productores que practican el riego por inundación son calificados como usuarios ineficientes.

Los discursos de eficiencia no solo categorizan nominalmente a distintos tipos de usuario sino que tienen efectos concretos en la distribución desigual del agua. Esto se evidencia en la promoción del Estado de grandes proyectos que buscan hacer uso de los excedentes de las fuentes de agua superficial para recargar el acuífero de Ica y Villacurí, aun cuando los pequeños agricultores beneficiarios de las fuentes que se buscan derivar también sufren de escasez hídrica ${ }^{8}$. Grandes esfuerzos e inversiones se realizan en este escenario, frente a la imposibilidad lógica que representan las propuestas para la recuperación del acuífero que impliquen un retroceso en los niveles de producción y rentas de la agroexportación, tales como el cambio de la cartera de cultivos o el endurecimiento en la regulación estatal. Como explicaba un funcionario del ALA Ica:

Las empresas no van a cambiar la forma de riego porque esa forma de riego es la óptima, por goteo. Lo que sí puede ayudar es buscar cultivos alternativos que requieran menos cantidad de agua, pero eso es imposible porque el espárrago es uno de los cultivos que más agua consume y que más divisas genera para el agroexportador y para el Perú. En ese escenario, la forma como ayudar a la recarga sería solo mediante grandes proyectos y que, por decir, de los cuatro meses que circula agua, circulen seis, hasta ocho meses al año para que ahí se pueda ayudar a la recarga (funcionario ALA ICA),

Sin embargo, según las juntas de aguas subterráneas, la sola tecnificación del riego no asegura la eficiencia en el uso del agua. Para esto es necesario que exista

7 Los informes de la agencia agraria de Ica muestran que la superficie sembrada de espárrago y vid, cultivos con un consumo de agua de $15000 \mathrm{~m}^{3}$ y de $10000 \mathrm{~m}^{3}$ por hectárea, para el mes de julio de 2014 sumaban casi 20000 hectáreas, superando por mucho el área y consumo de agua de cultivos tradicionales como el algodón y el maíz amarillo.

8 Como es el caso del Proyecto de Afianzamiento Hídrico Río Pisco-Río Seco, que busca conducir los excedentes del río Pisco, ubicado en la provincia de Pisco, para la infiltración en las pampas de Villacurí, en la provincia de Ica. 
una buena gestión, caracterizada por la valoración económica del agua y la administración empresarial de las organizaciones de usuarios (comisiones y juntas). En esta línea, es necesario que los operadores tengan conocimiento técnico pero también la capacidad financiera suficiente para mantener y eventualmente mejorar la infraestructura que poseen, y evitar así el desperdicio del recurso y la pérdida del acceso al agua subterránea. Tal como señalaba un directivo de la JUASVI

[...] las juntas administradoras de saneamiento que dan servicio de agua potable cobran una tarifa que no cubre ni siquiera los costos de operación y mantenimiento. Entonces, ¿cómo pueden ellos, cuando colapsa el pozo, reponerlo? Ese tipo de organización deficiente también contribuye al problema que por muchos es visto como «el agua en Ica se acabó», «tal zona se quedó sin agua». Pero si perforas un pozo al costado, sale agua. El tema es que el pozo ya cumplió con su vida útil y la gestión asociada a ese pozo no es la adecuada (directivo JUASVI).

Sin embargo, las juntas y comisiones de agua superficial $-\mathrm{y}$ excepcionalmente de subterránea ${ }^{9}$, que tienen como usuarios principalmente a pequeños productores - manejan una lógica distinta. Para estas, el agua no es algo que pueda ser valorado únicamente en términos económicos, sino que es considerada como un derecho cuyo acceso debe ser facilitado a todos sus usuarios. En este marco, las juntas y comisiones evitan el alza en las tarifas de agua para mantenerlas al alcance de sus miembros, e incluso subvencionan las tarifas de aquellos que encuentran dificultades para afrontar la retribución económica establecida. Tal como comentaba un directivo de la Comisión de Pozos de Pachacútec:

Nosotros mismos «vendemos el agua», pero damos un precio justo que nos permite solamente cubrir la necesidad del pago de energía y personal. Pero al menos estamos subsistiendo [...] De todas maneras como nosotros somos pequeños agricultores, el usuario paga su agua al contado, y a veces, cuando a algunos les flaquea la economía, en los estatutos está establecido que pueden acogerse a un crédito pero que lo tienen que pagar antes de que llegue el otro turno. Para eso se les da la facilidad, porque somos usuarios, somos copropietarios todos (dirigente de la Comisión de Usuarios Pozos de Pachacútec).

9 Caso de la Comisión de Pozos de Pachacútec. Esta comisión hace uso de agua subterránea, pero maneja un sistema similar al de las comisiones de agua superficial al conducirla por medio de canales a las parcelas de sus socios, los cuales son en su mayoría pequeños y medianos agricultores que practican riego por inundación. 
En un marco donde el conocimiento técnico y la buena gestión del agua se consideran como un capital de las juntas y usuarios de aguas subterráneas, los agroexportadores, a través de la JUASVI, han buscado intervenir y tomar la iniciativa en la gestión de los recursos hídricos superficiales. Así, por ejemplo, en el año 2014, la JURLACH, la JUDRI y la JUASVI firmaron un convenio mediante el cual la última apoyó en la gestión de los recursos hídricos y transfirió importantes fondos para la elaboración de estudios, ejecución de obras y construcción de infraestructura, como la ampliación de canales, bocatomas y descolmatación de canales. A cambio, la JURLACH y la JUDRI autorizaron el uso de excedentes de sus fuentes de agua para que sean utilizados en los proyectos de recarga artificial diseñados y ejecutados por la JUASVI. Tal como mencionaba un directivo de JUASVI:

La gestión del agua superficial tiene muchas aristas que no han sido debidamente atendidas por las organizaciones que competen, así que hemos tenido que involucrarnos también en ella, porque definitivamente influye en la recarga. Una adecuada gestión del recurso hídrico superficial definitivamente influye positiva o negativamente en la recarga, por eso hemos estado trabajando desde 2010 con un mayor énfasis en el apoyo de la gestión del recurso hídrico superficial (directivo de la JUASVI, énfasis nuestro).

Por otro lado, los agroexportadores, a través de sus juntas de usuarios, tienen una capacidad técnica suficiente como para generar información sobre las fuentes de agua de Ica y ejecutar proyectos propios. Paralelamente, los esfuerzos del Estado por generar información y gobernar el recurso han sido bloqueados en diversas ocasiones o se han visto obstaculizados por la rigidez de sus esquemas presupuestarios y capacidades ejecutivas.

Las juntas de usuarios de agua subterráneas, sobre todo la JUASVI, han generado iniciativas propias para facilitar la gestión sobre los recursos hídricos dentro de su jurisdicción. Ellos, a diferencia de la ANA, cuentan con recursos propios, personal con alta capacidad técnica y autonomía presupuestaria. Además, al representar a los agroexportadores, cuentan con información certera y actualizada sobre la existencia de pozos y volúmenes de explotación en sus distritos de riego. Entre sus principales avances están la elaboración de uno de los primeros censos de pozos - incluso antes del primer censo oficial de 2007-, la creación de un sistema de información abierta sobre precipitaciones y nivel de los embalses en las zonas altas de la cuenca, y la ejecución de proyectos de recarga propios con la construcción de 125 pozas de infiltración en un área de $369263 \mathrm{~m}^{2}$ dirigidas a la recarga artificial del acuífero. 
Por su lado, la ANA, a pesar de los esfuerzos realizados en los años 2007, 2010 y 2014 por consolidar una base de datos sobre la cantidad de pozos y sus características, hasta hoy no ha logrado concretar un censo confiable. Esto se debe a que muchos agroexportadores han negado sistemáticamente el ingreso de las autoridades a sus propiedades, en un escenario donde más de la mitad de usuarios de agua subterránea son informales ${ }^{10}$. Asimismo, no existen estudios oficiales detallados sobre el acuífero y hasta hoy se desconoce la dinámica de su funcionamiento, así como sus reales dimensiones y puntos de recarga ${ }^{11}$. Según los funcionarios de la ANA, la deficiencia de información se debería a la imposibilidad de ejecutar estudios por su cuenta, así como a los limitados esquemas presupuestales y plazos que maneja.

La capacidad técnica y el manejo de información superior de las juntas de usuarios de aguas subterráneas han posicionado a los agroexportadores como referentes en la gestión de los recursos hídricos subterráneos de Ica: actualmente son considerados como actores con autoridad para negociar y proponer cursos de acción al Estado. Así, la JUASVI ha buscado más de una vez asumir el costo y la ejecución de estudios técnicos encomendados a la ANA, proponiendo convenios de cooperación interinstitucional. Hasta el momento, estos ofrecimientos no se han concretado debido a la resistencia de algunos funcionarios a permitir la injerencia de las empresas agroindustriales en funciones públicas. Aun así, la información generada por la JUASVI, actualizada y de alto nivel técnico, es tomada por la ANA como referencia y punto de partida para sus propias iniciativas. Evidencia de esto es el caso del proyecto de recarga del acuífero llevado a cabo por la ANA como parte de la implementación del Plan de Gestión del Acuífero de Ica, Villacurí y Lanchas. Tal como comentaba un directivo de JUASVI:

Ellos [la ANA] lo que están haciendo ahora con su programa de recarga es que han agarrado parte de nuestra área de recarga y están haciendo todo un proyecto, pero en el papel, porque hasta ahora no hay fondos para ejecutar lo que ellos han diseñado. Nosotros seguimos limpiando los canales para abastecer esas zonas de recarga, contratamos al personal, recargamos de día o de noche, en el momento en que haya agua. Y todo eso es trabajo de la

10 Según la revista institucional de la AAA Cháparra Chincha, en 2013 de los 815 pozos identificados en el valle de Ica y los 442 de Villacurí, 615 y 442 infringían alguna norma respectivamente.

11 El Plan de Gestión del Acuífero de Ica, Villacurí y Lanchas habría incluido el levantamiento de esta información dentro de sus objetivos, sin embargo hasta el momento no se presentan los resultados finales de los estudios, a pesar de haberse dado por concluido el período de ejecución del Plan. 
JUASVI. Nosotros tenemos sistemas para medir el agua que ingresa, los caudales, los tiempos; trabajamos con datos del SENAMHI de evaporación para ver recarga efectiva. Como somos fiscalizados por ellos, ellos reciben toda la información, pero es un trabajo que operativa y técnicamente lo dirige y ejecuta la JUASVI. Y lo digo frente a ellos siempre, porque ellos cada vez que pueden dicen «recarga y limpieza: este año se ha recargado...» y sacan nuestros datos. Pero ellos deberían decir que es un trabajo realizado por la JUASVI. Igual, cuando vino el hidrogeólogo español, fui a Lima a la conferencia y dijo «el trabajo que viene haciendo la ANA». ¿Cuál es el trabajo que viene haciendo la ANA?, digo yo. ¡Dios mío! [...] La ANA tiene la información, porque nosotros se la pasamos y ellos a veces la difunden como el trabajo de la autoridad, pero ellos no pagan ni un sol de ese trabajo (directivo de JUASVI).

En un contexto donde el enfoque técnico-científico del agua es predominante, el grupo agroexportador, mediante la incorporación de discursos de eficiencia y uso racional del agua en sus prácticas productivas, logra legitimarse como el actor con autoridad para establecer las bases correctas para el manejo de los recursos hídricos. En un escenario de estrés hídrico, el discurso de la eficiencia, además, permite relativizar el problema definiéndolo ya no como un problema pérdida de disponibilidad del agua subterránea a causa de la sobrexplotación por la agroindustria, sino como un problema de ineficiencia de los pequeños productores en sus prácticas de riego, manejo de tecnología y gestión de sus organizaciones. El grupo agroexportador se permite reclamar el derecho prioritario de controlar los recursos hídricos subterráneos y superficiales de Ica y continuar con su explotación.

\section{Capacidad coercitiva: represión, sanción y regulación}

Dentro de un marco institucional que favorece y protege la inversión privada, y gracias al acceso privilegiado a asesoría legal con conocimiento experto sobre la normativa y procedimientos administrativos que regulan la actuación de las autoridades del agua, el grupo agroexportador ha logrado doblegar la frágil capacidad de regulación de la Estado y la sociedad civil, reprimiendo sus esfuerzos por distintos medios.

Desde la emisión de la RJ-330 en el año 2011, que ratificó las vedas de pozos en Ica, Villacurí y Lanchas ${ }^{12}$ y prohibió la emisión de licencias de uso de

12 Desde su instauración por resolución ejecutiva del gobierno regional de Ica en el año 2005, estas vedas han ido expandiéndose en la provincia y cada vez son más restrictivas. 
agua subterránea, la labor de los funcionarios de las ALA se ha concentrado en la detección de perforaciones ilegales de pozos u obras de profundización y de pozos no inventariados, así como la fiscalización de pozos que no contaran con caudalímetros, que extrajeran volúmenes de agua mayores de los otorgados o que operaran sin licencia de uso de agua, con el fin de ejecutar medidas correctivas en la forma de multas de hasta 10000 unidades impositivas tributarias ${ }^{13}$ - UIT y la clausura de pozos.

Tal como en el caso de los censos, los agroexportadores del valle de Ica y de las pampas de Villacurí han usado su potestad sobre la propiedad privada para impedir la verificación del estado y número de sus pozos a los funcionarios de las ALA. Incluso, por demanda de los usuarios, hoy en día el procedimiento para realizar la vigilancia obliga a los funcionarios de las ALA a notificar a los usuarios con tres días de anticipación antes de realizar una inspección. Esto último limita la capacidad de sanción de las autoridades, ya que, por un lado, muchos agroexportadores reprograman indefinidamente las inspecciones, mientras que otros aprovechan el tiempo para encubrir sus infracciones.

En los pocos casos en los que los funcionarios han decidido realizar visitas inopinadas o ingresar a los fundos sin la autorización directa de los agroexportadores, han sido denunciados por abuso de autoridad. Estas denuncias, en muchos casos, exceden el ámbito administrativo y se extienden a largas disputas judiciales donde las contrapartes se encuentran en una clara desigualdad de recursos políticos y económicos. Los funcionarios encuentran estas denuncias particularmente dañinas para su reputación, estabilidad laboral y futuro profesional, ya que consideran que «manchar» su expediente con denuncias de mala actuación afecta su imagen personal y recorta sus posibilidades de ascender dentro de la institución, sobre todo cuando algunos puestos son cargos de confianza.

Las denuncias por abuso de autoridad ya se han vuelto una estrategia institucionalizada para resistir la regulación del uso del agua subterránea entre los agroexportadores del valle de Ica y Villacurí, y tal como señalaba un funcionario de la ALA, para ellos se han vuelto parte del oficio. De este modo, mecanismos que buscaban proteger a los usuarios frente a la actuación inadecuada de funcionarios públicos han sido apropiados por los agroexportadores, transformándose en armas de intimidación para reprimir las acciones de vigilancia y sanción de las ALA. Como señalaba los funcionarios de la ALA Ica y Río Seco:

13 Una UIT asciende a S/. 3950 para el año 2016. 
[...] hay trabajadores que han recibido denuncias en Río Seco por ir a hacer una notificación, ni siquiera les han permitido ingresar y los han denunciado por abuso de autoridad, por simplemente querer ir a ver. Al final nunca nos abrieron la puerta, pero nos han denunciado (funcionario ALA Ica).

Tenemos a los Benavides, Forsyth, Ventin, Joaquín Ormeño, una serie de gente que tiene poder político y poder económico. Y a veces nosotros, como autoridad, nos hemos sentido un poco reducidos al chocar con ellos y no poder realizar nuestras funciones. Nos cierran las puertas y no podemos entrar (funcionario ALA Río Seco).

Incluso cuando los funcionarios han llegado a emitir sanciones, la apelación en el Tribunal de Controversias Hídricas - THC ha sido el siguiente recurso para evadir su cumplimiento. En estos casos, los agroexportadores han aprovechado los errores cometidos por los funcionarios públicos, sea en la diligencia (registro de la visita, uso de distintivos, identificación del funcionario, notificación de la visita al propietario, entre otros) o en la formulación de la denuncia. Lo común es que, mediante esta acción, los agroexportadores logren la reducción de la multa e incluso su anulación total. Por ejemplo, el gráfico 1 muestra que, del total de apelaciones resueltas dentro del período 2014-2016 y publicadas en el portal de la ANA, un $70 \%$ obtuvo la reducción o anulación de la sanción establecida por las autoridades.

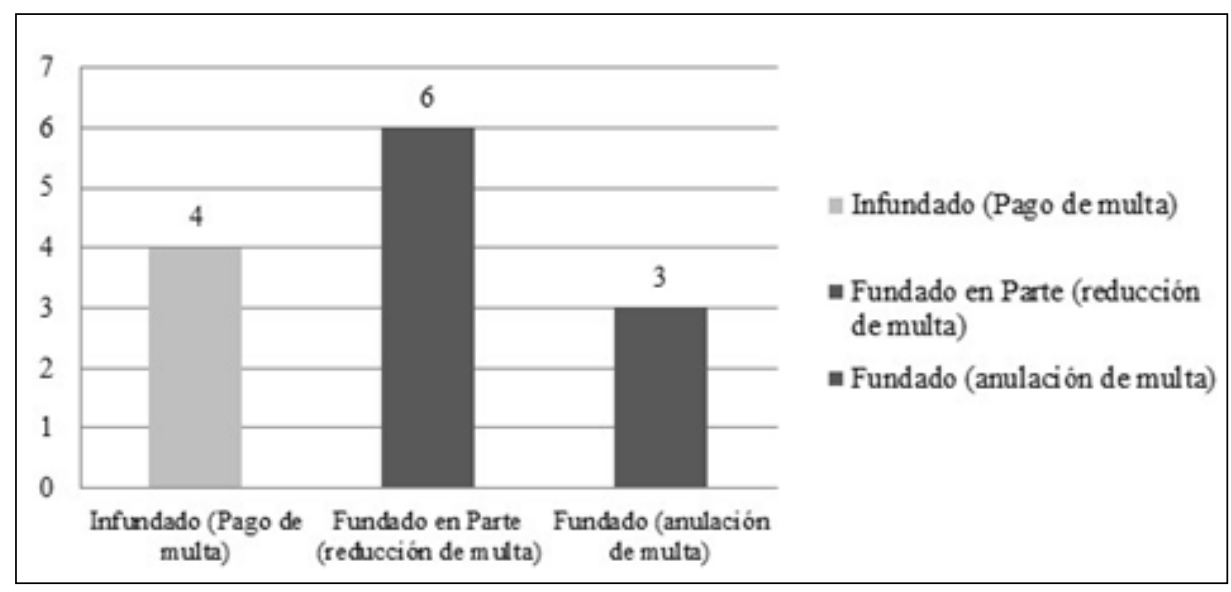

Gráfico 1. Apelaciones a procedimientos administrativos con resoluciones publicadas (2014-2016). Fuente: resoluciones del TCH publicadas en la página web de la ANA 2016. Elaboración propia. 
En un marco donde la capacidad de sanción y vigilancia de los funcionarios del Estado es exitosamente resistida por los agroexportadores y donde el ejercicio de su autoridad sobre los usuarios los hace, paradójicamente, susceptibles a ser sancionados, algunos funcionarios han buscado evadir la ejecución de acciones que los pongan en malos términos con los agroexportadores locales. Otros tantos han optado por establecer relaciones de cooperación con estos, facilitando irregularmente el otorgamiento licencias de uso de agua y la incorporación de pozos nuevos en los inventarios, así como brindando información a los agroexportadores para que evadan las acciones de vigilancia y sanción, con el fin de obtener favores o evitar sanciones. Tal como señalaba un funcionario de la ALA Río Seco:

El tema de Río Seco es que, como le digo, a los ingenieros les quemaban los expedientes, o no sabían cómo resolverlo y lo escondían. Yo creo que no querían comprometerse [...]. No hemos podido detectar quiénes han sido, pero hemos detectado que los usuarios a través de la Junta nos decían «tal persona ha hecho algo, tal persona ha hecho algo». Tal vez facilitando información para el beneficio de algún usuario. Si se está abriendo un PAS [proceso administrativo sancionador], que alguien de acá llame y diga «por si acaso están yendo y no los dejen entrar», o sacando copias de expedientes. Por eso se ha instalado [en la oficina de ALA Río Seco] un sistema de vigilancia con cámaras (funcionario ALA Río Seco).

Asimismo, los agroexportadores son reconocidos como actores que en el ámbito local poseen la capacidad legítima de hacer uso de la violencia bajo el argumento de la defensa de la propiedad privada ${ }^{14}$. En el espacio del fundo son los agroexportadores los que gobiernan. Estos espacios suelen están amurallados, muestran carteles que advierten «propiedad privada» y «orden de disparar»y cuentan con tranqueras y personal de seguridad para restringir el acceso a personas no autorizadas. En este escenario, los funcionarios de las ALA reconocen ser susceptibles a sufrir agresiones físicas en el cumplimiento de sus labores:

Todavía muchos agroexportadores son reacios a que la autoridad ingrese a verificar, porque no quieren pagar más. Entonces, nosotros actualmente estamos tomando diferentes acciones: frente a una negativa de acceso: levantamos un acta, lo notificamos al infractor y paralelamente vamos con una medida cautelar, para que el juez disponga el orden de ingreso. Ya no nos aventuramos a querer entrar a que de repente nos metan bala, nos golpeen, hemos sido denunciados por abuso de autoridad (funcionario AAA Cháparra Chincha).

14 Sobre la privatización del poder coercitivo ver: Kamphuis, C. (2011). 
Fuera del fundo, la capacidad de ejercer violencia en contra de quienes se oponen a sus intereses se puede ampliar hacia los espacios que recorre su infraestructura. En este escenario, el uso de la violencia física por los agroexportadores no es sancionado por el Estado - incluso en muchos casos es justificado-, que no interviene o interviene directamente en favor de las empresas y en defensa de la propiedad privada. Ejemplo de esto fueron los acontecimientos ocurridos en el contexto de una protesta ciudadana en contra del tendido de una tubería para trasladar agua del centro poblado El Tambo a un fundo de una empresa agroexportadora ubicada en el centro poblado Pinilla:

Ellos empezaron el día 12 a cavar; el pueblo se levantó e hizo retirar las máquinas para poner los tubos. Pero ahorita ellos tienen su gente de mal vivir, tenían como 38 personas de mal vivir entre hombres y mujeres. Ahorita me dicen que tienen como quince, yo ya no he ido, pero la primera vez sí los he contado. Por decir, si yo voy a no dejarlos trabajar, ellos amenazan con su machete, se acercan como para quererte agredir. Eso es de la empresa que trae la gente, esa gente viene pagada por la empresa (dirigente del frente de defensa de los RRHH de Ocucaje).

De este modo, las acciones tanto desde el Estado como desde la sociedad civil para detener la sobrexplotación ilegal de los recursos hídricos subterráneos de Ica y Villacurí son exitosamente reprimidas por el grupo agroexportador bajo el argumento de la defensa de la propiedad privada. En un contexto de estrés hídrico, la imposibilidad de regular a los usuarios o lograr que estos se autorregulen contribuye a la continuidad de la sobrexplotación del acuífero y la agudización de los escenarios de escasez hídrica.

\section{CONCLUSIONES}

¿Cómo los agroexportadores han concentrado poder hídrico en Ica? y ¿cómo éstos ejercen este poder? fueron las preguntas que guiaron esta investigación. A partir de las tres dimensiones de poder hídrico, el texto ha mostrado el proceso por el cual los agroexportadores han logrado obtener el control y acceso poco restringido a los recursos hídricos subterráneos de Ica.

La capacidad económica del grupo agroexportador se ha traducido en poder hídrico, dado que las fuertes inversiones para la perforación o compra de pozos y la implementación de riego tecnificado han permitido que el recurso se concentre en las manos de los usuarios con mayores recursos. Por otro lado, la valoración económica del agua promovida por el Estado refuerza la primacía del grupo 
agroexportador, al priorizar el acceso al agua a quienes puedan pagar por ella. Esto, sumado a la situación de estrés hídrico generada por la explotación intensiva del agua subterránea por la agroexportación, ha generado escenarios de escasez y desposesión entre los productores de menores recursos, restringiendo el acceso a esta fuente particular de agua (Harvey, 2005).

La capacidad técnica caracterizada por el uso de riego tecnificado y el manejo de información certera y actualizada sobre el acuífero y usuarios se traduce en poder hídrico, ya que permite que estos alcancen legitimidad frente al Estado y la sociedad civil como usuarios eficientes y activos en la generación de iniciativas para la recuperación del acuífero. En una situación de estrés hídrico, el discurso de eficiencia permite relativizar el problema de la escasez, volviéndolo una consecuencia ya no de la sobreexplotación del acuífero por los agroexportadores sino de la ineficiencia de los usuarios de menores recursos, reclamando en este proceso el derecho legítimo de los primeros para controlar los flujos del agua subterránea y superficial.

La capacidad coercitiva se traduce en poder hídrico en la medida en que, sobre la base de un marco normativo que protege la inversión privada, el grupo agroexportador ha construido mecanismos de represión con el fin de evadir la regulación de la sociedad civil y del Estado sobre su uso de los recursos hídricos subterráneos. Paradójicamente, mediante un uso perverso de mecanismos legales, los agroexportadores han logrado que en algunos casos sean incluso los mismos funcionarios públicos los que se autorregulen y evadan encabezar actividades de regulación y vigilancia del uso del agua subterránea por miedo a sanciones sociales, económicas e incluso físicas.

El ejercicio de las tres dimensiones de poder por los agroexportadores, en el marco de la aplicación de políticas neoliberales, se ha traducido en una privatización de facto de los recursos hídricos subterráneos de Ica y Villacurí. Esta situación se caracteriza por la concentración de la infraestructura hidráulica mediante la perforación o compra de pozos en un contexto de veda, el acceso preferencial a los recursos hídricos basado en el discurso de eficiencia y la preminencia de los regímenes de valoración económica del agua y la poca regulación o la regulación restringida al uso de los recursos hídricos subterráneo por las agroexportadoras gracias a la resistencia exitosa frente a los intentos de control del Estado.

El texto muestra, además, que en este proceso el Estado ha delegado facultades consideradas como exclusivas, tales como el ejercicio de la violencia y la potestad sobre los recursos hídricos. Planteamos que esto sucedería por tres razones. 
Primero, los agroexportadores se han instaurado en Ica como un grupo dominante dentro de la configuración social de Ica, es decir, aquel que sobre la base de su legitimidad obtiene el consenso de la mayoría de la sociedad para imponer la dirección general de la vida social según sus propios valores (Harvey, 2005; Gramsci, 1999). Los agroexportadores en Ica se han constituido como tales gracias a su capacidad financiera y técnica en el marco de un discurso compartido con el Estado de eficiencia en el uso del agua y dinamización de la economía regional y nacional. Gracias a esto han obtenido un consenso generalizado dentro del Estado y la sociedad civil en torno a la idea de que ellos están en las mejores condiciones para establecer las bases del desarrollo regional, y tienen carta abierta para definir los medios para cimentar este desarrollo y establecer las reglas en el uso del agua subterránea.

Segundo, el Estado, a través de sus diversas instancias, que a su vez cuentan con diferencias en cuanto a peso político y económico, maneja distintas lógicas y políticas que, para el caso de la agroexportación en Ica, han resultado ser incompatibles. Así, por un lado, mantiene una política de conservación de los recursos hídricos y el acuífero, mientras que por otro, fomenta la inversión privada y dinamización de la economía a costa de su sobrexplotación. En este marco, cuando el Estado ha buscado regular, ha enfrentado serias deficiencias técnicas, presupuestales y políticas para generar información certera sobre el acuífero y sus usuarios. Siguiendo a Scott $(1998,2005)$, esto habría creado una situación de ilegibilidad que ha imposibilitado el gobierno de los recursos hídricos y sus usuarios por el Estado.

Tercero, desde la implementación de las políticas neoliberales el Estado ha virado hacia una racionalidad de mercado, fomentando la autorregulación en los ciudadanos (Ferguson, 2009). En la gestión pública del agua, esto se ha traducido en la promoción de una «cultura de agua» ${ }^{15}$. Sin embargo, el Estado falla en incorporar esta cultura en la práctica de los agroexportadores, dado que el poder regulador y sancionador estatal, necesario para imponer la agenda de conservación del agua subterránea de Ica (Agrawal, 2005; Birkenholtz, 2009), se ve sobrepasado por el poder hídrico agroexportador y su agenda económica-productiva. En este escenario, el discurso de la eficiencia es apropiado y manipulado por los agroexportadores, quienes a la vez que sobreexplotan el acuífero son considerados como usuarios eficientes que generan divisas y, por lo tanto, tienen intereses coin-

$15 \mathrm{http} / /$ www.iagua.es/noticias/peru/ana-peru/15/02/26/que-es-cultura-agua-que-promueve-anaperu 
cidentes con el Estado. Esto genera que, aún en circunstancias de estrés hídrico, los agroexportadores logren mantener el control y acceso casi desregulado de los recursos hídricos subterráneos del valle de Ica y Villacurí.

¿Cómo recuperar el carácter público del agua subterránea en este escenario? Sostenemos que es necesario generar un balance de poderes en torno a la gestión del agua subterránea de Ica y Villacurí. La primera vía sería fortalecer la institucionalidad estatal del agua en el nivel local, haciéndola capaz de conducir la senda del desarrollo hídrico y ejercer su rol de regulación y sanción, y que sea reconocida como legítimo custodio del agua como bien público (Bebbington y Bury, 2010, p. 72). La segunda vía pasa por empoderar a la sociedad civil, en particular a los diversos usuarios de Ica y Villacurí que compiten por el uso y acceso al agua subterránea, para la creación de espacios de contingencia y regulación mutua entre usuarios, así como entre estos y el Estado.

Para que esto sea posible, es necesario tomar en cuenta que la locación del agua subterránea se encuentra embebida en las relaciones de poder e intereses de diversos actores estatales y no estatales, por lo que es necesario incorporar un enfoque que priorice la equidad en lugar de la eficiencia y productividad, como parte integral de la formulación e implementación de la políticas del agua (Boelens y Arroyo, 2013; Hoogesteger, 2015).

\section{REFERENCIAS BIBLIOGRÁFICAS}

Agrawal, A. (2005). Environmentality. Technologies of government and the making of subjects. Michigan: Duke University Press.

Bebbington, A. y J. Bury (2010). Minería, instituciones y sostenibilidad: desencuentros y desafíos. Anthropológica, XXVIII(28), 53-84.

Birkenholtz, T. (2009). Groundwater Governmentality: Hegemony and Technologies of Resistance in Rajasthan's (India). The Geographical Journal, 175(3), 208-220. https://doi.org/10.1111/j.1475-4959.2009.00327.x

Boelens, R. (2011). Luchas y defensas escondidas: pluralismo legal y cultural como una práctica de resistencia creativa en la gestión local del agua en los Andes. Anuario de Estudios Americanos, 68(2), 673-703.

Boelens, R., A. Arroyo, A. (2013). Introducción: El agua fluye en dirección del poder. En A. Arroyo y R. Boelens, Aguas robadas: despojo hídrico y movilización social. Quito: Abya Yala, IEP, Justicia Hídrica.

Boelens, R., D. Getches y A. Guevara Gil (2006). Agua y derecho: politicas hídricas, derechos consuetudinarios e identidades locales. Lima: IEP, 2006. 
Bourdieu, P. y J.C. Passeron (2001). Fundamentos de la violencia simbólica. En Pierre Bourdieu y Jean-Claude Passeron, La reproducción. Elementos para una teoría del sistema de enseñanza, Libro 1 (pp. 15-85). Madrid: Popular.

Instituto Nacional de Estadística e Informática - INEI (1994). III Censo Nacional Agropecuario. http://censos.inei.gob.pe/bcoCuadros/IIIcenagro.htm. Recuperado en enero de 2016.

Instituto Nacional de Estadística e Informática - INEI (2012). IV Censo Nacional Agropecuario. http://censos.inei.gob.pe/Cenagro/redatam/. Recuperado en enero de 2016.

Damonte, G. (2015). Redefiniendo territorios hidrosociales: control hídrico en el valle de Ica, Perú (1993-2013). Cuadernos de Desarrollo Rural, 12(76), 109-133. https://doi.org/10.11144/Javeriana.cdr12-76.rthc

Damonte, G., E. Pacheco y C. Grados (2014). Dinámicas de concentración y escasez de agua: el boom agroexportador y los pequeños propietarios en las zonas medias y altas del río Ica. En G. Damonte y M.T. Oré (eds.), ¿Escasez de agua?: retos para la gestión de la cuenca del río Ica (pp. 121-171). Lima: PUCP.

Dargent, E. (2015). Technocracy and democracy in Latin America. Nueva York: Cambridge University Press. https://doi.org/10.1017/CBO9781107446663

Das, Veena y Deborah Poole (2004). Anthropology in the margins of the state. Santa Fe, N.M.: School of American Research Press.

Denzin, N. y Y. Lincoln (2011). The SAGE Handbook of Qualitative Research, $4^{\text {th }}$ ed. Washington: Sage.

Durand, F. (2003). Riqueza económica y pobreza política: reflexiones sobre las élites del poder en un país inestable. Lima: Fondo Editorial PUCP.

Durand, F. (2005). La mano invisible en el Estado: efectos del neoliberalismo en el empresariado y en la política. Lima: DESCO, Friedrich Ebert Stiftung.

Durand, F. (2012). El debate sobre la captura del Estado peruano. En Perú Hoy: la gran continuidad (pp. 19-56). Lima: DESCO.

Ferguson, J. (2009). The Uses of Neoliberalism. Antipode, 51(41), 166-184. https://doi. org/10.1111/j.1467-8330.2009.00721.x

Foucault, M. (1992). El orden del discurso (traducción de Alberto González Troyano). Buenos Aires: Tusquets.

Foucault, M. (2001). Vigilar y castigar: nacimiento de la prisión. México DF: Siglo Veintiuno, 2009.

Foucault, M. (2006). Governmentality. En A. Sharma y A. Gupta, The Anthropology of the State (pp. 131-143). India: Blackwell Publishing Ltd. 
Gómez, R. (2008). Agricultura comercial moderna en el Perú: el caso de la agricultura de exportación no tradicional (1995-2007). En G. Damonte, B. Fulcrand y R. Gómez (eds.), Perú: problema y posibilidad, SEPIA XII (pp. 499-552). Lima: SEPIA.

Gramsci A. (1999). Selection from the prison notebooks. Nueva York: International Publishers.

Guber, R. (2001). La etnografía. Método, campo y reflexividad. Bogotá: Norma.

Hammersley, M y P. Atkinson (1994). Etnografía. Métodos de investigación. Barcelona: Paidós.

Harvey, D. (1990). La condición de la posmodernidad: investigación sobre los orígenes del cambio cultural. Buenos Aires: Amorrortu.

Harvey, D. (2005). Nuevo imperialismo: acumulación por desposesión. Socialist register 2004 (enero de 2005). Buenos Aires: CLACSO

Helmke, G. y S. Levistky (2003). Informal Institutions and Comparative Politics: A Research Agenda. Working Paper 307. Kellog Institute.

Hoogesteger, J. (2015). Intensive groudwater use and (in)equity: processes and governance challenges. Environmental Science \& Policy, 51, 117-124. https:// doi.org/10.1016/j.envsci.2015.04.004

Kamphuis, C. (2011). La extracción extranjera de recursos mineros y la privatización del poder coercitivo: un estudio de caso sobre la Empresa de Seguridad Forza. Apuntes, 68. Centro de Investigaciones de la Universidad del Pacifico, 63-108.

Marshall, A. (2014). Apropiarse del desierto: agricultura globalizada y dinámicas socioambientales en la costa peruana. Lima: Instituto Francés de Estudios Andinos.

Migdal, J.S. (1988). Strong Societies and Weak States: State-society relations and state capabilities in the Third World. Princeton: Princeton University Press.

Muñoz, I. (2015). Adaptación y debilidad del Estado: el caso de la escasez de agua subterránea en Ica. Revista de Ciencia Política y Gobierno, 2(4), 2016, 47-66.

Oré M.T., D. Bayer; J. Chiong y E. Rendón (2012). La guerra por el agua en Ica, Perú. El colapso del agua subterránea. En E. Isch, R. Boelens y F. Peña (eds.), Agua, injusticia y conflictos. Lima: IEP, PUCP, Justicia Hídrica y CBC.

Oré, M.T.; G. Damonte (2014). Escasez de agua en la cuenca del río Ica. Lima: PUCP.

Patriau, E. (2014). El Congreso peruano: políticas públicas e influencia informal sobre la burocracia. Perfiles latinoamericanos, 22(43), 103-126. Recuperado el 16 de junio de 2015. https://doi.org/10.18504/pl2243-103-2014

Peña, F. (2011). Acumulación de derechos de agua en México: el poder de las élites. En Rutgerd Boelens, Leontien Cremers, Margreet Zwarteveen (eds.), Justicia 
hídrica. Acumulación, conflicto y acción social, cap. 12 (pp. 209-224). Lima: Instituto de Estudios Peruanos, Fondo Editorial PUCP.

Perreault, T. (2007). De la «guerra del agua» a la «guerra del gas»: gobernabilidad de recursos, neoliberalismo, y protesta popular en Bolivia. En Carlos Crespo y Susan Spronk (eds.), Después de las guerras del agua en Bolivia (pp. 147-182). La Paz: CESU-UMSS/ Plural Editores.

Perreault, T. (2013). ¿Despojo por acumulación? Minería, agua y justicia social en el Altiplano boliviano. En A. Arroyo y Rutgerd Boelens (eds.), Aguas robadas: despojo hídrico y movilización social. Quito: Abya Yala/IEP.

Scott, J.C. (1998). Seeing like a state: how certain schemes to improve the human condition have failed. New Haven: Yale University.

Scott, J.C. (2005). Cities, People and Language. En A. Sharmay A. Gupta (eds.), The anthropology of the state: a reader (pp. 247-269). Malden, MA: Blackwell.

Sindzingre, A. (17-18 de septiembre, 2004). The Relevance of the Concepts of Formality and Informality: A Theoretical Appraisal. En EGDI and UNU-WIDER Conference Unlocking Human Potential: Linking the Informal and Formal Sectors. Helsinki, Finland.

Springer, S. (2012). Neoliberalising violence: of the exceptional and the exemplary in coalescing moments. Area, 44, 136-143. https://doi.org/10.1111/j.14754762.2012.01084.x

Swyngedouw, E. (2004). Social Power and the Urbanization of Water: Flows of Power. Oxford: Oxford University Press.

Swyngedouw, E. (2006). Power, Water and Money: Exploring the Nexus. Human Development Occasional Papers 2006/14. Human Development Report Office.

Wester, P. y J. Hoogesteger (2011). Uso intensivo y despojo del agua subterránea: hacia una conceptualización de los conflictos y concentración del acceso al agua subterránea. En R.A. Boelens, L. Cremers y M.Z. Zwarteveen (eds.), Justicia hídrica: acumulación, conflicto y acción social (pp. 105-133). Lima: Justicia Hídrica/ IEP/Fondo Editorial PUCP.

Wittfogel, K.A. (1957). Oriental despotism: A comparative study of total power. New Haven: Yale University Press.

Wortser, D. (1985). Rivers of Empire.Water, Aridity, and the Growth of the American West. New York: Pantheon Books.

Yacoub, C., B. Duarte y R. Boelens (2015). Reflexiones: despojo del agua e hidroeléctricas. En B. Duarte, R.A. Boelens y C. Yacoub López (eds.), Agua y ecología. El extractivismo en la agroexportación, la minería y las hidroeléctricas en Latinoamérica. Quito: Instituto de Estudios Peruanos - IEP, 2015. Agua y Sociedad, 22). 